\title{
Discussion on Universal Ethics in Virtual World
}

\author{
Xiang Xiaojun \\ College of Marxism, Wuhan University of Technology, Wuhan 430070, China \\ xxjflint@aliyun.com
}

Keywords: virtual world, ethics, virtual subjects, universal ethics

\begin{abstract}
Based on introduction to characteristics of virtual world, this paper discussed several extremely shocked customs and traditions (e.g. gender, marriage and family relations) in ethics field. It pointed out that although virtual world is beneficial for free show of personality, instincts and desires of ethical subjects, it requires ethical subjects to obey social morality and universal ethics viewed from its globality, sociality, openness and integration.
\end{abstract}

\section{Introduction}

Ethical issue has been mainly limited to human field in past over 2,000 years since Socrates. Even Hegel viewed it as the law of human beings and god when he tended to be religious. But he viewed ethics as a real kingdom of human beings (both alive and dead) when investigating it as a real spirit. Of course, ethics studies expand to life circle after entered into the $20^{\text {th }}$ century and the bioethics was proposed. Later, the post-modern ethics was developed in the industrial society. However, all of these ethics are mainly limited in real world. Researches on ethics in virtual world began just several years before. Therefore, this paper emphasizes on discussing ethics in virtual world.

\section{Characteristics of virtual world}

Virtual world, the complex of information society, virtual reality and network world, refers to a new world full of humanistic spirits in the $20^{\text {th }}$ century. It is evolved by applying previous "digital world" and "ideal world" onto a real stage with advanced technical means, information resources and imagination. It is not only an infinite conception of time and space brought by electronic information revolution, network and virtual technology, but also an red-blooded open system integrating light, electricity, color, energy, digit and information. With an active structure, it could extend and integrate new nodes infinitely, thus facilitating innovation and evolution of network continuously.

Space form of virtual world is cyberspace. "Cyberspace is not composed of one homogeneous space, but refers to countless quickly expanding spaces. Each space provides a unique digital interaction and digital communication form." ${ }^{[1]}$ Cyberspace gives us a real experience of dialectical unity that "space is sensibility of insensibility and the insensibility of sensibility". Time form of virtual world is cybertime. It is not the real time or time perceived by "the existent in the world", and has no "historic significance of the moment" and "ordinariness related with cumbersome". ${ }^{[2]}$ "As the uniform of existence and nonexistence", "it is the pure form of sensibility or intuitiveness."

${ }^{[3]}$ Based on cybertime, "on one hand, information that flows around the world quickly mixes field reports across neighbors and provides unprecedented immediacy for social events and cultural manifestation". ${ }^{[4]}$ On the other hand, mixture of different time forms creates collage time, which makes time have no start, end and sequences. This makes cyberspace complicated and confusing, and relevantly reflects that "act-by-oneself is the windy basis of existence". As a result, "oneself, act-by-oneself and their relation are maintained within an infinite free boundary". ${ }^{[5]}$

It is subjectivity, imagination, virtuality, hyperspace, storage, openness, high efficiency, condensation and self-adjustment of virtual world that reflects the unity of opposites in the virtual world, such as existence and nonexistence, real and virtual, subjective and objective, visible and 
invisible. It fully proves that the nature of virtual world is "a transcoding". In other words, "it is transpositions from one code to another one; from one language level to another; and from one language to another language." ${ }^{[6]}$ Such continuous transpositions make the virtual world cover politics, economy, cultural education and ethics of human societies gradually.

\section{Several impacted traditional ethics}

The great practical significance and historical significance of virtual world changes social pictures about human survival and development revolutionary. "It changes our way of birth, life, learning, working, production, consumption, dream, fighting or death fundamentally". [7] Today, politics, economy, military and culture are step into the global new era in a hurry. Meanwhile, dark forces in the world, such as criminal activities, terrorist organizations and extreme spirits are marching toward globalization and informatization. Both dark and bright humanities are portraying themselves freely in the virtual world, which will impact ethics, ideology and corresponding view of life and values in real society. In the ethics field, customs and traditions that are significantly challenged include:

Gender, marriage and family relations. Since human civilization increasingly evolves from physical power $\rightarrow$ brain power $\rightarrow$ mechanical force $\rightarrow$ mechanical brain $\rightarrow$ electric power $\rightarrow$ computer, the dominant role of males with physical advantages weakens day by day. Patriarchy that governs human beings for thousands of years is significantly impacted and the male-dominated era fell apart gradually. Feminism doesn't need real revolution and organizations of various extensive "seize power" activities. With the arrival of information society as well as increasingly realization of language investment and language governance, females will replace males in many fields of human society gradually and acquire equal rights with males. Many office organizations and homes have realizes computer networking nowadays. In future, individuals, home and society will be connected comprehensively through man-machine and automation of more homes, which will make all individual behaviors and social activities extremely easy on the Internet. Complete liberation of women will come true with the appearance of virtual world. Moreover, gender relation in political economy, cultural education and ethics will become balance and stable day by day.

Correspondingly, the traditional monogamy and patriarchal system will be impacted significantly with the appearance of the virtual world and various cyber love forms. A profound sexual revolution is inevitable under the promotion of virtual reality. The goal of this sexual revolution is to abolish male chauvinism and integrate bisexual subculture or original isolated bisexual experiences; re-examine sex characters of male and female and reevaluate their advantages and disadvantages. Abolishment of sexual role and women's economic empowerment will not only reduce patriarchy families and end women's powerless condition, but also give women more freedoms and tear the traditional family structure into pieces. The traditional marriage will be replaced by "willing partnership" completely. If such "sexual revolution is succeeded, the overpopulation problem which seems difficult to be solved at present will disappear, because it is closely related with woman's libration". ${ }^{[8]}$ Additionally, sufficient freedom in the network society will scour off the stigma of "ruined women". Man and woman will enjoy the same moral standard and develop similar morality and personality, rather than that women's obedience and softness are caused by men's absolute authority at present. In the real world, women start their journey of "citizen death" once got married. They leave the social stage and get back to their small families. However, such constraint doesn't exist in virtual world. Women will learn, work, communicate and live like men through networks.

Relationship between adult and children. In human history, inequality between adult and children is even more serious than gender inequality. Popper once said acutely that "Today, only children is still the biggest unfortunate stage. In short, adults are committing crimes in front of children". ${ }^{[9]}$ In particular, film and TV arts about wars, violence, crime passionnel and terrorist activities are infecting and poisoning children continuously, making them living in an extremely reechy environment. Parents and teachers who case children a lot feel powerless under the increasingly globalization no matter how hard they worked to resist social power formed by adults. Nowadays, children are completely occupies by network games full of passion and attractions. It is easy to 
conclude that children have become a quenchless victim of adults. Currently, to abolish the damaged and alienated old concept that children must obey to adults, adults shall try to get a scientific understanding on nature of children, so that they could abandon evil governance on children, give full play of children's real look and provide them a healthy, happy and wonderful childhood. Poisoning and polluting children is the crime to the whole human being. Child is a free subject that deserves various rights and adult shall give children more free time and space to experience the nature and life, rather than force them to accept adults' idea of "always right" and things.

Interpersonal relationship. "A bosom friend afar brings a distant land near". In the virtual world, a good wish could become a wonderful reality. The real world becomes more and more limited for continuously developing desires of human beings. However, many things within though and sight but beyond reach could be realized in the virtual world by using modern telecommunication and virtual technologies. Many traditional ethics and family values restrict relatives and interpersonal communication. But the virtual world is full of daily life and humanity contents. People are free to play games, chat, communicate, make comments, appreciate of beauty, visit friends, send blessings to others, establish a romantic relationship, get married and start career. There are no strangers but friends. In the real world, it requires abundant money and time and even will face numerous difficulties to communicate with friends around the world. But this is easy in network. People could achieve the most intimate body and physical contacts in the virtual world through transmission and transformation of sound, images, languages and information. Two lovers afar from each other in geographic distance could stay in the same screen and tell their feelings. Without geographic distance and different space-time properties, the virtual world offers people a wider motion space and more communication time, survival opportunities, choices as well as bigger clubs. Every one is a member of big family and experiences family affection and fickleness of the world directly.

Finally, new search, identification and construction concerning global flow of wealth, power and image, individual privacy, social supervision, information share, cyber love safety, network openness as well as various relation issues between individual and collective, religion and ethnic group, nation and social politics and philanthropism begin. For example, power politics is opposite against philanthropism in real world, which is the main reason of philanthropism failure in reality. But in virtual world, packaging of concealed subject often will stimulate its kindness and develop sympathy and generosity. Moreover, there's no fundamental conflict of interest between virtual subjects, such as difference and estrangement caused by color, nation, gender, nationality, position, reputation and money. Therefore, it is easier to establish and maintain philanthropism in network society than in real world. No one has the right to deprive right of love and loved of virtual subjects in the virtual world, regardless of their gender, age, color and physical abilities. Because identity between acknowledge and practice subjects is one principal contradiction and universal standard of behavior in the virtual world. People will re-investigate and re-organize of these things. Basic teachings including Christian, Islamism, Judaism and Buddhism will be impacted significantly in virtual world. Based on this comprehension, Manuel-Custer, a Spanish sociologist, predicted boldly that "informational society is the world of Japanese Aum Doomsday Cult viewed from its global manifestation, the theocracy ambition of American militia, Islamism and Christian, and the world of mutual genocide of Hutu/Tusi (Burundi)". ${ }^{[10]}$

\section{Ethical subjects in virtual world have to obey social morality and universal ethics}

Although virtual world is beneficial for free manifestation of personality, instincts and desires of ethical subjects, its globality, sociality, openness and integration obviously requires ethical subjects to obey to social morality and universal ethics. Due to the design of related functions, any wrong doing may bring irreparable harms to the whole network world. However, coerciveness of laws is often helpless to concealed subject of crimes. Therefore, perfecting network technologies and ideological quality as well as conscience of network subjects are the basis to maintain safety and order of virtual world. In this way, internalized universal ethics will highlight its charm and spontaneous constraint more. At this moment, the internal power of reason makes every ethical 
subject be able to follow game rules and the universal ethics conscientiously in daily life.

Virtual subjects often possess more humanity, honesty and exposure, which is the key to change the universal ethics in virtual world from general principle into reality or from general reality into principle. Although virtual subjects have virtuality, hypothesis, guess and inference, they possess human reality. Many ideas and behaviors of virtual subjects are natural expression of consciousness and emotion, free intelligent creation, natural show of instincts, desires and free will. Virtual world could achieve perfect and full humanity really. Currently, many people are keen on net socialization, online games, net chat and cyber love, which proves that virtual reality could meet curiosity and thirst for knowledge of numerous people, and gives them more free spaces than in real world.

Virtual world is characteristic of incorporeity, hyperspace, storage, universality, high efficiency, economical efficiency, condensation, self-adjustment and operability, thus enabling to provide more possibility, practicability and reality for universal ethics. In particularly, the increasing abstraction, symbolization, digitalization, normalization and formalization of virtual world will contribute the biggest convenience and more opportunities for implementation of the universal ethics. In the conceptual space-time realized through coding and abstract, various virtualized specifics are higher than reality and history. Therefore, virtual world needs the universal ethics and the universal ethics will change into reality automatically.

Systematic and rapid virtual world is easier for virtual subjects to communicate and play the "theater" role. Therefore, universal ethics and mutual coordination, interaction and understanding are very necessary. In virtual world, structural elements in daily life world, that is, reproduction activities of culture, integration process of the society as well as social behavior of individuals, will get rid of constraints of real social system or social system and play more freely, thus forming a new situation of "revolutionization of reasonable culture" and "exploitation of living world". As a result, human culture and the living world enter into a higher-level stage. Under the shield of a more tolerant and humanized universal ethics, daily life in virtual world will become more colorful, adventurous, exciting, transparent and open. Of course, people will gain more happiness from it. They will become more conscious to adopt normal attitude, adjust the internal relationship between the subjective world and individuals legally to making their intentions, wishes and emotions adapt better to external world and social objects in the "unforced" network communication. In the virtual world, people will see a "player who is fully devoted into his own play. He will take it seriously that his play is real and a true "reality"". This further proves that human constructing virtual world is not to abandon the real world, but for understanding, reconstructing, adapting and making up the real world better. With respect to continuously developing desires of human beings, the real world becomes limited to meet human demands and it needs human beings to create more worlds to serve them. Limited by human bodies, people can witness the whole universe secrets and enjoy free lives under the assistance of modern high technologies.

\section{Conclusions}

Today, philosophical thinking of human beings on life is no long a novel observation. It changes messy real world into a thinking order. Virtual world is a new world that idealizes and regularizes reality and idea based on human life. It reflects that human subject evolves into a new level. As the product of human beings' idea, concept and language structure, it not only represents formation rule and balance form of cognition, but also reveals dynamic theoretical practicability of human beings.

\section{References:}

[1] C.JL.Frank: Reality and Human Beings. Zhejiang People's Publishing House, 2002, P3.

[2] Martin Dodge and Rob Kitchin, Mapping Cyberspace. London, 2001. P. 1.

[3] Martin Heidegger, Being and Time. Sanlian Bookstore (1987), P394.

[4] Hegel, Natural Philosophy. Commercial Press, 1986, P47. 
[5] Manuel Custer, Rising of Network Society. Social Scientific Literature Press, 2001, P561.

[6] B. C. van Fraassen, Scientific Image, Clavendon, 1986, P. 21.

[7] Frederick·Jameson, Cage of Language. Hundred Flower Pond Press, 1995, P178.

[8] Kate·Millette, Sexual Politics. Jiangsu People's Publishing House, 2000, P82.

[9] David·Miller, Open Idea and Society, Jiangsu People's Publishing House, 2000, P450.

[10] Habermas, Theory of Communication Action. Chongqing Publishing House, 1994, P133. 